\title{
Celiac disease, wheat allergy and non celiac gluten sensitivity
}

\author{
Iman Nasr ${ }^{1 *}$, Ikram Nasr ${ }^{2}$, Latifa Al Shekeili ${ }^{1}$, Humaid A Al Wahshi ${ }^{3}$, Mohammad H Nasr $^{4}$ and Paul J Ciclitira ${ }^{5}$ \\ ${ }^{1}$ Specialist in Immunology and Allergy, Royal Hospital, Muscat, Oman \\ ${ }^{2}$ Consultant gastroenterologist, Guy's and St Thomas' hospital London, UK \\ ${ }^{3}$ Senior Consultant in Rheumatology, Immunology and maternal medicine, Royal Hospital Muscat, Oman \\ ${ }^{4}$ Student of Bachelor sciences, Oman Medical College, Muscat, Oman \\ ${ }^{5}$ Paul J Ciclitira, Consultant gastroenterologist, Guy's and St Thomas' hospital, London, UK
}

\begin{abstract}
Wheat and gluten related disorders are common and differentiating between these conditions is necessary to identify the appropriate management, and establish potential complications and ways to avoid them. Celiac disease (CD) is a gluten related enteropathy where the villi of the small bowel flatten resulting in nutrition malabsorption when at risk individuals are exposed to gluten. This condition is completely reversible once gluten is eliminated entirely from the diet. Non celiac gluten sensitivity (NCGS) on the other hand is used to describe individuals who report gastrointestinal symptoms when exposed to gluten and are managed by eliminating gluten from their diets. It is important to differentiate between NCGS and CD as the former group do not suffer consequences of malabsorption or other serious complications if they continue to ingest toxic gluten. Wheat allergy is a condition caused by immunologic responses to a range of different proteins in wheat and is managed by eliminating wheat from diet. Symptoms range from urticaria, chest tightness, gastrointestinal symptoms and wheeze to anaphylaxis which makes dietary elimination. In this article, we describe the three wheat related disorders, investigation and management.
\end{abstract}

\section{Introduction}

Wheat is one of the most widely consumed food products worldwide. It is also responsible for many disorders, some of which are benign and others, if left untreated, may have serious consequences. Wheat (Triticum aestivum, Tri a) proteins and classified into water soluble proteins: globulins and albumins, and water insoluble protein: gluten which consists of two main types: glutenins and gliadins [1]. The glutenins are mainly responsible for the dough elasticity and the gliadins for the extensibility of bread. Gluten has been involved in the pathogenesis of some conditions such as celiac disease (CD), nonceliac gluten sensitivity (NCGS) and wheat allergy. The latter includes wheat dependent exercise-induced anaphylaxis (WDEIA), eosinophilic esophagitis (EoE) and atopic dermatitis. In this article we will focus on the difference between celiac disease, non-celiac gluten sensitivity and wheat allergy. It is important to differentiate CD from NCGS to establish the group at risk of nutritional deficiencies and other complications of CD. Apart from aiming to prevent these compilations, it is necessary for the individuals who are at risk of complications to be aware of the importance of adherence to a strict gluten free diet. Similarly, it is crucial to identify the group of patients who are allergic to wheat and formulate an appropriate treatment plan to avoid fatal allergic reactions such as those that occur in WDEIA.

\section{Celiac disease}

CD (also known as gluten-sensitive enteropathy) is a chronic systemic, autoimmune disorder in genetically predisposed individuals triggered by exposure to dietary gluten and resulting in mucosal inflammation, villous atrophy and crypt hyperplasia. Therefore, the predisposed individuals are at risk of villous atrophy when ingesting wheat, barley and rye. The typical presentation is that of malabsorption, anemia and gastrointestinal disturbance, including diarrhea, bloating and nutritional deficiencies. Traditionally, the disease presented in children with malnourishment and delayed growth after gluten is introduced in the diet. Currently, and in view of the availability of serological screening for $\mathrm{CD}$, more cases with nonspecific gastrointestinal symptoms. CD is identified. The prevalence of CD is approximately $1 \%$ of the Caucasian population [2]. Genetically, CD is associated with human leukocyte antigen (HLA) haplotypes DQ2 (in $95 \%$ of patients) and DQ8 (in 5\% of patients) [3].

Untreated CD is associated with significant morbidity and an up to 4 -fold increase in risk of death [4]. Morbidity is linked to the effects of nutritional deficiencies on the general health, for example deficiency in calcium and vitamin D leads to osteopenia and osteoporosis, and anaemia associated with iron deficiency. Other nutritional deficiencies include zinc and vitamin B deficiencies. Hyposplenism is a one of the recognised complication and can result in severe infections. Between $2-5 \%$ of individuals with $\mathrm{CD}$ may develop dermatitis herpetiformis which usually improve with adequate management of $\mathrm{CD}$, although it may require treatment with dapsone if it persists. Severe complications of $\mathrm{CD}$ are not common but are potentially very serious. Ulcerative jejunitis is seen in non-responsive $\mathrm{CD}$ and can results in structuring small bowel disease and some patients require surgery to resolve this. Small bowel lymphoma risk increases in patients where CD is not managed adequately [5].

\section{Diagnosis}

Serology tests using specific endomysial antibodies (EMA) or

Correspondence to: Iman H Nasr MD, MRCP (UK), Specialist in Immunology and Allergy, Royal Hospital, Muscat, Oman, E-mail: drimannasr@gmail.com

Received: July 06, 2016; Accepted: July 26, 2016; Published: July 30, 2016 
immunoglobulin A (IgA) anti-tissue transglutaminase (a-TTG) should be used as the first line investigation in those with compatible symptoms. It is used to screen high-risk populations such as firstdegree relatives of $C D$ patients. Figure 1 summarizes the recommended steps in diagnosing celiac disease [6].

About $2 \%$ of the celiac population are IgA deficient and hence may have false negative serology results [7]. In this case, antiImmunoglobulin G (IgG) TTG antibodies should be tested. False negative serology results can also occur if the patient has already started a gluten free diet. Histology is the gold standard for diagnosing CDand for assessing the degree of tissue damage. It is also a valuable told to monitor if there is any improvement particularly if the symptoms are nonspecific or persistent. Histologically, [8] the findings may be classified based on modified Marsh criteria (Table 1) [6]. In a few patients in whom the diagnosis is unclear HLA DQ2 and DQ8 haplotyping is requested. About $95 \%$ of the population is HLA DQ2 or DQ8 positive, but as many as $55 \%$ of them does not have $\mathrm{CD}$. This suggests that the HLA testing alone is not useful for diagnosing CD in adults, but it aids as a negative predictor $[9,10]$.

\section{Treatment}

Strict elimination of gluten from the diet is the only accepted management for $\mathrm{CD}$. In addition to this, it is necessary to monitor the nutritional status of patients and to correct any vitamin and nutrient deficiencies. It may be necessary for some celiac patients to add nutritional supplements to their diet to replenish deficiencies, such as calcium and vitamin D supplements, iron replacement therapy and some vitamins such as B vitamins. Individuals with $\mathrm{CD}$ will usually undergo a bone mineral density scan during their follow up to screen for osteopenia and osteoporosis. In view of the risk of hyposplenism, patients with $\mathrm{CD}$ should be offered prophylactic pneumococcal vaccination to avoid the risk of serious infections]. It is important to be aware that gluten free breads and similar products are low in fibre and high in fats to make these products more palatable. Hence, patients are advised to increase their fibre intake and adjust their daily calorie intake to avoid unfavourable weight gain.

\section{Wheat allergy}

Wheat allergy is caused by immunologic responses to a range of different proteins in wheat. These can be Immunoglobulin E (IgE)mediated (immediate) and/or non IgE-mediated (delayed) allergic reactions to wheat.

Table 1. Modified Marsh Criteria

\begin{tabular}{|l|l|l|l|}
\hline $\begin{array}{l}\text { Marsh } \\
\text { classification }\end{array}$ & $\begin{array}{l}\text { Intraepithelial } \\
\text { lymphocytes (IEL) } \\
\mathbf{> 3 0}\end{array}$ & Crypts & Villi \\
\hline Marsh 0 & Normal & Normal & Normal \\
\hline Marsh 1 & Increased & Hyperplasia & Normal \\
\hline Marsh 2 & Increased & Hyperplasia & $\begin{array}{l}\text { Villous atrophy: } \\
\text { a) Mild } \\
\text { b) Subtotal } \\
\text { c) Total }\end{array}$ \\
\hline Marsh 3 & Increased & & \\
\hline Marsh 4 & Total mucosal hypoplasia (rare) & \\
\hline
\end{tabular}

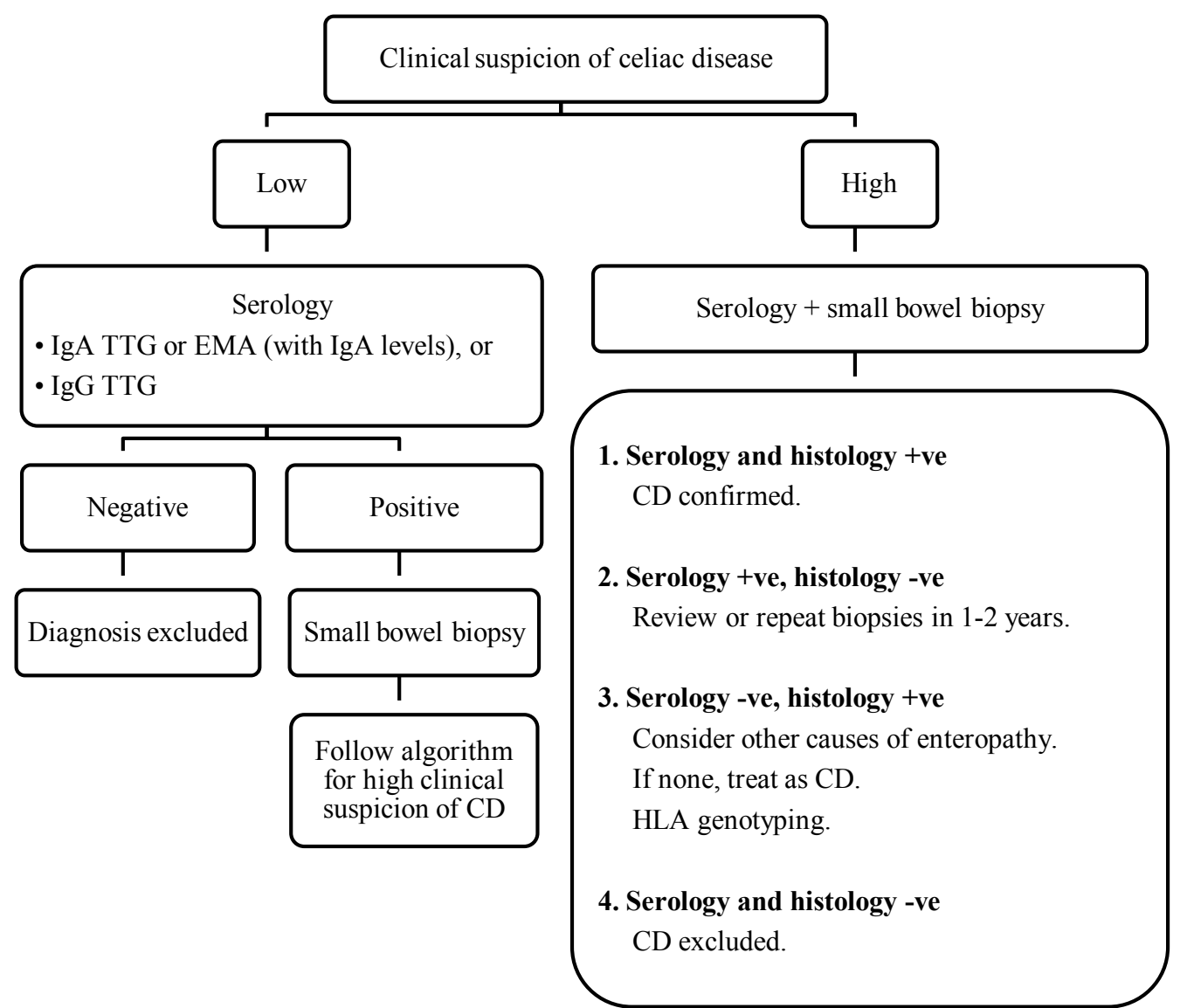

Figure 1. Algorithm for diagnosing celiac disease (IgA: Immunoglobulin A, TTG: Tissue transglutaminase antibody. EMA:endomysial antibody, +ve: positive, -ve: negative, CD: Celiac disease, IgG: Immunoglobulin G). 
IgE-mediated wheat allergy is estimated to occur in 0.2 to $1.3 \%$ of children in Europe [11] and 0.4\% of children in the US [12]. Symptoms develop within minutes to few hours from the time of ingestion. It occurs as a result of formation of specific IgE to one or more of the proteins found in wheat grain (globulins and albumins, glutenins and gliadins) $[13,14]$. This causes mast cells and basophils to release vasoactive mediators resulting in typical allergic symptom. This includes generalized symptoms such as rash, itching, angioedema or worsening eczema; respiratory system in the form of chest tightness, difficulty in breathing, wheeze and stridor as what occurs in baker's asthma; gastrointestinal symptoms such as abdominal pain, diarrhea and vomiting; and cardiovascular system disturbances with tachycardia and hypotension. An example for anaphylaxis is WDEIA, where omega 5-gliadin (a protein component in gluten) is the major allergen causing anaphylaxis [15]. In this condition, anaphylaxis is triggered by exercising within minutes to a few hours after the ingestion of wheat products, rather than occurring as a result of wheat ingestion per se. Although the mechanism is not fully understood, a possible explanation is that omega- 5 gliadin-derived peptides are cross-linked with tissue transglutaminase (tTG), which causes a marked increase in IgE antibody binding both in-vitro and in-vivo. Activation of tTG in the intestinal mucosa during exercise in patients with WDEIA may lead to the formation of large allergen complexes capable of eliciting anaphylactic reactions [16].

Many proteins in wheat responsible for the IgE mediated food allergy and respiratory allergies have been identified. Triticum aestivum (Tri a 37) and nonspecific lipid transfer protein (nsLTP or Tri a 14) are associated with severe allergy. Thioredoxins (Tri a 25), serine proteinase inhibitor (Tri a 29), thaumatin-like proteins, $\alpha-, \beta$, $\gamma$-, $\omega$-gliadins; and low-molecular-weight (LMW) glutenin subunits all appear to be implicated in IgE-mediated allergy to wheat [1]. Alphaamylase inhibitor (Tri a 28 and Tri a 29) is one of the most important wheat allergen in IgE-mediated food allergy in the water soluble albumin/globulin fractions $[14,15,17]$ and is implicated in baker's asthma.

Non-IgE mediated wheat allergic reactions usually occur after 2 hours of ingestion. They present as subacute or chronic symptoms affecting one or more systems:

- Gastrointestinal tract: such as eosinophilic gastrointestinal disorder, food protein-induced proctitis/proctocolitis, food proteininduced enterocolitis syndrome (FPIES), protein-induced enteropathy and Celiac disease.

- Skin: such as dermatitis herpetiformis characterized by an itchy papular eruption over the extensor surfaces of the knees and elbows, buttocks, sacrum, face, neck, and trunk.

Some food allergy disorders can have both immunoglobulin E (IgE) and non-IgE-mediated components and, as in the case of non IgE-mediated reactions, are typically isolated to the gastrointestinal tract and/or skin. These include atopic eczema [18,19], eosinophilic oesophagitis and eosinophilic gastroenteritis [20].

\section{Diagnosis}

Figure 2 summarises the recommended steps to diagnose wheat allergy. A detailed clinical history of the reaction is important in establishing the diagnosis. In order to support a diagnosis of IgEmediated reactions, skin prick test to wheat and /or in-vitro tests with specific IgE to wheat is performed. If skin testing with commercial wheat extract is negative, then a prick- prick test with fresh wheat

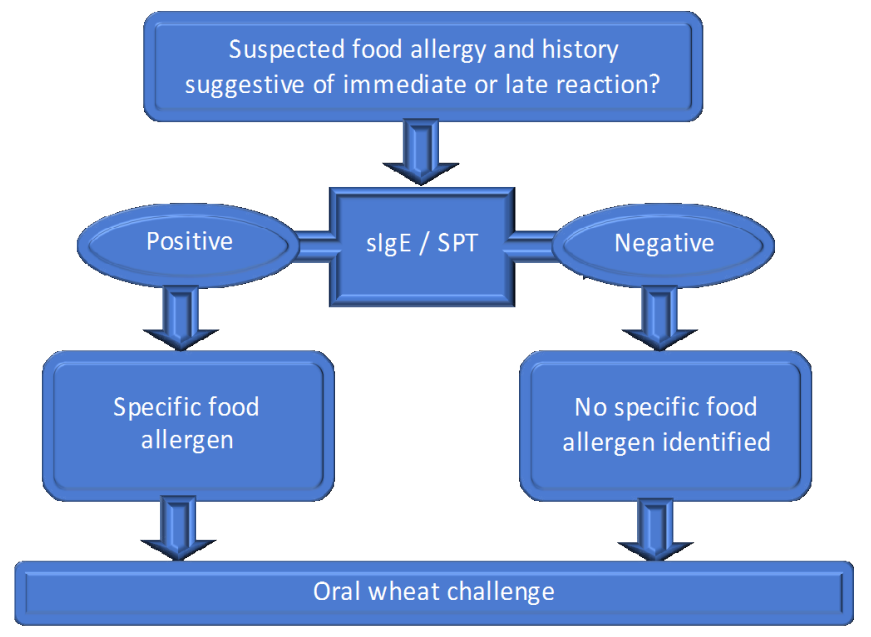

Figure 2. Algorithm for the diagnosis of wheat allergy (sIgE: specific IgE, SPT: skin prick test).

product, for example wheat flour or high gluten flour mixed with saline to make a paste, should be performed. The wheat product is pricked with a testing lancet, and then the cleaned skin of the volar forearm is pricked. Skin testing has good sensitivity and specificity (92\% and $84 \%$ respectively) [21]. In-vitro tests measure the levels of specific IgE to wheat; however this has a low positive predictive value mainly due to cross-reactivity with grass pollen which shares common IgE epitopes. Furthermore, not all wheat proteins are included in this diagnostic test [1]. Component resolved testing (ImmunoCAP, Thermo Fisher Scientific) commercial assay identifies true sensitization from crossreactivity to wheat through the measurement of $\operatorname{IgE}$ to defined allergens rather than the whole extract. Serum IgE to recombinant omega-5 gliadin is available and may be positive even when IgE to wheat is negative [22]. It has a $91 \%$ sensitivity and $92 \%$ specificity for wheat-related allergic symptoms [22] making this immunoassay more clinically relevant than those for wheat, gluten, or other wheat allergens [23]. It is also predictive of severe reactions to wheat in children [24]. Component resolved testing may eliminate the need for an oral food challenge (OFC) with wheat or gluten. OFC may be necessary in some cases where the reaction is still highly suggestive of an IgE mediated reaction but in vivo and in-vitro tests are negative. It is also used in confirming the diagnosis in non-IgE mediated reactions where $\operatorname{IgE}$ test are often negative. Atopy patch testing may be useful in cases of atopic dermatitis [25] but unfortunately there are neither standardized reagents available nor guidelines for interpretation of atopy patch testing results.

OFCs are performed carefully and cautiously by an allergy specialist through gradual feeding of the test food (wheat, gluten flour or bread) under close observation. The test helps in confirming the diagnosis and rules out conditions that can mimic an IgE mediated food allergy. In some cases OFC is preceded by a period of wheat elimination to see if this ameliorates the symptoms.

\section{Treatment}

In true wheat allergy, appropriate dietary avoidance is the key management of wheat allergy. Such patients should have access to appropriate dietetic counselling, ideally by a dietician experienced in food allergy.

In wheat dependent, exercise-induced anaphylaxis (WDEIA) 
Table 2. Comparison of Gluten-Related Disorders (IgE: Immunoglobulin E)

\begin{tabular}{|l|l|l|l|}
\hline Condition & Celiac disease & Wheat allergy & Non celiac gluten sensitivity \\
\hline Characteristics & Genetic, autoimmune & IgE mediated or non IgE mediated reactions & $\begin{array}{l}\text { Unknown, probably adaptive immune response } \\
\text { involved }\end{array}$ \\
\hline Symptoms & $\begin{array}{l}\text { Abdominal pain, bloating, diarrhea, fatigue, } \\
\text { symptoms of malabsorption }\end{array}$ & $\begin{array}{l}\text { Urticaria, rash, itching, swelling, nausea and vomiting, } \\
\text { anaphylaxis }\end{array}$ & $\begin{array}{l}\text { Abdominal pain, bloating, diarrhea, fatigue, mental } \\
\text { fogginess, muscle aches. }\end{array}$ \\
\hline Tests & Serology and histopathology & $\begin{array}{l}\text { Skin prick test and Serology: specific IgE to gliadin, specific } \\
\text { IgE to omega 5-gliadin (in IgE mediated reactions) Oral food } \\
\text { challenge }\end{array}$ & $\begin{array}{l}\text { Diagnosis of exclusion followed by an oral food } \\
\text { challenge test }\end{array}$ \\
\hline Treatment & Strict Gluten free diet & Strict wheat/gluten free diet & Gluten/wheat free diet variable adherence level \\
\hline
\end{tabular}

patients should avoid the wheat for at least four to six hours before exercise. This can be achieved by exercising in the mornings before eating anything; although some patients find this very difficult in which listing the safe foods that can be eaten prior to exercising could be a reasonable option. All patients with WDEIA should carry an epinephrine auto injector for self-injection in case of anaphylaxis and educated on when and how to use it. A few published case reports suggest the use of high dose cromoglycates (cromolyn sodium taken orally $100 \mathrm{mg}$ in children and $200 \mathrm{mg}$ in adults 20 minutes before eating) may be useful in preventing attacks [26-29].

However, larger studies are needed and patients need to be informed about this so they must not rely upon this medication to protect them. The role of non-sedating second generation antihistamines (Cetrizine $10 \mathrm{mg}$, Fexofenadine $180 \mathrm{mg}$, or Loratidine $10 \mathrm{mg}$ orally once or twice daily taken 2 hours prior to exercising) may help reduce the symptoms but not prevent it. Patients must be aware for early symptoms such as flushing, itching, difficulty breathing and must stop exercising immediately if any of these occur and to self-administer epinephrine intramuscularly if needed.

\section{Non-celiac gluten sensitivity}

NCGS is a condition that produces a wide range of symptoms many of which are similar to that seen in CD. Symptoms are variable and include abdominal pain, bloating, fatigue, diarrhea or constipation in response to gluten ingestion, but they improve on a gluten free-diet. Symptoms reappear after a gluten challenge $[30,31]$.

The prevalence of NCGS is unknown as many patients with this disorder self-treat by avoiding gluten in their diets [32]. Some authors estimate the prevalence to be around $0.63-6 \%$ of the normal population [33-36].

It is not an allergy to wheat and unlike CD; this is not an autoimmune condition and does not lead to intestinal damage or malabsorption. Minor abnormalities in the intestinal mucosa were observed in some cases including mild inflammation with some lymphocytic infiltration rated as Marsh classification 0 or I. These changes have been recently referred to as lymphocytic enteropathy and have been also observed in food allergy [37]. In a study by Carroccio et al. [38 ], increased infiltration of duodenal lamina propria with eosinophils and activation of circulating basophils was seen in NCGS patients. The pathogenic mechanism is poorly understood and some studies suggest the role of the adaptive immune response [39].

\section{Diagnosis}

There are no laboratory markers specific to NCGS yet. Immunoglobulin $\mathrm{G}$ (IgG) antigliadin antibodies (AGA) are detected in only $56.4 \%$ of NCGS patients and in $81.2 \%$ of patients with CD [40]. Volta $e$ al. found that the IgG AGA disappeared in the vast majority of NCSG patients after gluten withdrawal but persisted in $40 \%$ of patients with CD. NCGS remains a diagnosis of exclusion and CDas well as wheat allergy need to be excluded. The diagnosis is then confirmed by an oral food challenge test.

\section{Treatment}

Apart from the symptomatic effects exposure to gluten has on individuals with NCGS, there is no serious health hazards associated with these conditions. Therefore, avoidance of gluten is the treatment of choice for symptom control. Noncompliance with the treatment has no known direct health concern.

\section{Summary}

It is important to differentiate between celiac disease, wheat allergy and non-celiac gluten sensitivity for prognostic reasons and because all have a different management strategy. Although it may not be easy to differentiate between some of these conditions clinically, a few clinical characteristics and laboratory tests may aid the diagnosis (Table 2). In contrast to celiac disease and wheat allergy, there are no laboratory markers for the diagnosis of non-celiac gluten sensitivity and therefore, is a diagnosis of exclusion. Celiac disease is associated with nutritional deficiencies and complications as a result of nutrient malabsorption. Wheat allergy may lead to a spectrum of diseases ranging from mild allergic reactions and gastrointestinal problems to severe or even fatal reactions such as anaphylaxis. Treatment involves managing the symptoms as well as strict avoidance of wheat. Non celiac gluten sensitivity mainly presents with gastrointestinal upset in response to gluten ingestion and responds to a gluten free diet and has no known health concern.

\section{References}

1. Tatham AS, Shewry PR (2008) Allergens to wheat and related cereals. Clin Exp Allergy 38: 1712-1726. [Crossref]

2. Rashtak S, Murray JA (2009) Celiac disease in the elderly. Gastroenterol Clin North Am 38: 433-446. [Crossref]

3. Castro-Antunes MM, Crovella S, Brandão LA, Guimaraes RL, Motta ME, et al (2011) Frequency distribution of HLA DQ2 and DQ8 in celiac patients and first-degree relatives in Recife, northeastern Brazil. Clinics (Sao Paulo) 66: 227-231. [Crossref]

4. Rubio-Tapia A, Kyle RA, Kaplan EL, Johnson DR, Page W, et al. (2009) Increased prevalence and mortality in undiagnosed celiac disease. Gastroenterology 137: 88-93. [Crossref]

5. Nasr I, Leffler DA, Ciclitira PJ (2012) Management of celiac disease. Gastrointest Endosc Clin N Am 22: 695-704. [Crossref]

6. Nasr I, Nasr I, Ciclitira PJ (2015) Patient management coeliac disease. Foundation year Journal. 9: 26-9.

7. Kumar V, Jarzabek-Chorzelska M, Sulej J, Karnewska K, Farrell T, et al. (2002) Celiac disease and immunoglobulin a deficiency: how effective are the serological methods of diagnosis? Clin Diagn Lab Immunol 9: 1295-1300. [Crossref]

8. Corazza GR, Villanacci V, Zambelli C, Milione M, Luinetti O, et al. (2007) Comparison of the interobserver reproducibility with different histologic criteria used in celiac disease. Clin Gastroenterol Hepatol 5: 838-843. [Crossref] 
9. Nasr I, Messing J, Nasr IH, Ciclitira PJ (2015) Chapter 19. Detection and control of gluten as a food allergen. Handbook of Food Allergen Detection and Control. 367-77.

10. Cecilio LA, Bonatto MW (2015) The prevalence of HLA DQ2 and DQ8 in patients with celiac disease, in family and in general population. Arq Bras Cir Dig 28: 183-185. [Crossref]

11. Venter C, Pereira B, Grundy J, Clayton CB, Roberts G, et al. (2006) Incidence of parentally reported and clinically diagnosed food hypersensitivity in the first year of life. J Allergy Clin Immunol 117: 1118-1124. [Crossref]

12. Gupta RS, Springston EE, Warrier MR, Smith B, Kumar R, et al. (2011) The prevalence, severity, and distribution of childhood food allergy in the United States. Pediatrics 128 e9-17. [Crossref]

13. Battais F, Pineau F, Popineau Y, Aparicio C, Kanny G, et al. (2003) Food allergy to wheat: identification of immunogloglin $\mathrm{E}$ and immunoglobulin $\mathrm{G}$-binding proteins with sequential extracts and purified proteins from wheat flour. Clin Exp Allergy 33: 962 970. [Crossref]

14. Pastorello EA, Farioli L, Conti A, Pravettoni V, Bonomi S, et al. (2007) Wheat IgEmediated food allergy in European patients: alpha-amylase inhibitors, lipid transfer proteins and low-molecular-weight glutenins. Allergenic molecules recognized by double-blind, placebo-controlled food challenge. Int Arch Allergy Immunol 144: 10-22. [Crossref]

15. Morita E, Matsuo H, Chinuki Y (2009) Food-dependent exercise-induced anaphylaxis -importance of omega-5 gliadin and HMW-glutenin as causative antigens for wheatdependent exercise-induced anaphylaxis. Allergol Int. 58: 493-8.

16. Palosuo K, Varjonen E, Nurkkala J, Kalkkinen N, Harvima R, et al. (2003) Transglutaminase-mediated cross-linking of a peptic fraction of omega-5 gliadin enhances IgE reactivity in wheat-dependent, exercise-induced anaphylaxis. $J$ Allergy Clin Immunol 111: 1386-1392. [Crossref]

17. James JM, Sixbey JP, Helm RM, Bannon GA, Burks AW (1997) Wheat alpha-amylase inhibitor: a second route of allergic sensitization. J Allergy Clin Immunol 99: 239-244. [Crossref]

18. Eller E, Kjaer HF, Høst A, Andersen KE, Bindslev-Jensen C (2009) Food allergy and food sensitization in early childhood: results from the DARC cohort. Allergy 64: 1023 1029. [Crossref]

19. Hon KL, Leung TF, Ching G, Chow CM, Luk V, et al. (2008) Patterns of food and aeroallergen sensitization in childhood eczema. Acta Paediatr 97: 1734-1737. [Crossref]

20. Roy-Ghanta S, Larosa DF, Katzka DA (2008) Atopic characteristics of adult patients with eosinophilic esophagitis. Clin Gastroenterol Hepatol 6: 531-535. [Crossref]

21. Le TA, Al Kindi M, Tan JA, Smith A (2016) The clinical spectrum of omega-5-gliadin allergy. Intern Med J 46: 710-716. [Crossref]

22. Park HJ, Kim JH, Kim JE, Jin HJ, Choi GS, et al. (2012) Diagnostic value of the serum-specific IgE ratio of Ï\% $\%$ gliadin to wheat in adult patients with wheat-induced anaphylaxis. Int Arch Allergy Immunol 157: 147-150. [Crossref]

23. Ito K, Futamura M, Borres MP, Takaoka Y, Dahlstrom J, et al. (2008) IgE antibodies to omega-5 gliadin associate with immediate symptoms on oral wheat challenge in Japanese children. Allergy 63: 1536-1542. [Crossref]

24. Ebisawa M, Shibata R, Sato S, Borres MP, Ito K (2012) Clinical utility of IgE antibodies to $\omega-5$ gliadin in the diagnosis of wheat allergy: a pediatric multicenter challenge study. Int Arch Allergy Immunol 158: 71-76. [Crossref]
25. Järvinen KM, Turpeinen M, Suomalainen H (2003) Concurrent cereal allergy in children with cow's milk allergy manifested with atopic dermatitis. Clin Exp Allergy 33: 1060-1066. [Crossref]

26. Juji F, Suko M (1994) Effectiveness of disodium cromoglycate in food-dependent exercise-induced anaphylaxis: a case report. Ann Allergy 72: 452-454. [Crossref]

27. Sugimura T, Tananari Y, Ozaki Y, Maeno Y, Ito S, et al. (2009) Effect of oral sodium cromoglycate in 2 children with food-dependent exercise-induced anaphylaxis (FDEIA). Clin Pediatr (Phila) 48: 945-950. [Crossref]

28. Aihara Y, Kotoyori T, Takahashi Y, Osuna H, Ohnuma S, et al. (2001) The necessity for dual food intake to provoke food-dependent exercise-induced anaphylaxis (FEIAn): case report of FEIAn with simultaneous intake of wheat and umeboshi. J Allergy Clin Immunol 107: 1100-1105. [Crossref]

29. Ueno M, Adachi A, Shimoura S (2008) A case of wheat-dependent exercise-induced anaphylaxis controlled by sodium chromoglycate, but not controlled by misoprostol. $J$ Environ Dermatol Cutan Allergol. 2: 118

30. Sapone A, Bai JC, Ciacci C, Dolinsek J, Green PH, et al. (2012) Spectrum of glutenrelated disorders: consensus on new nomenclature and classification. BMC Med 10: 13. [Crossref]

31. Biesiekierski JR, Newnham ED, Irving PM (2011) Gluten causes gastrointestina symptoms in subjects without celiac disease: a double-blind randomized placebocontrolled trial. Am J Gastroenterol. 106: 508-14.

32. Catassi C, Bai JC, Bonaz B, Bouma G, Calabrò A, et al. (2013) Non-Celiac Gluten sensitivity: the new frontier of gluten related disorders. Nutrients 5: 3839-3853. [Crossref]

33. Di Sabatino A, Corazza GR (2012) Nonceliac gluten sensitivity: sense or sensibility? Ann Intern Med 156: 309-311. [Crossref]

34. Sapone A, Lammers KM, Mazzarella G, Mikhailenko I, Cartenì M, et al. (2010) Differential mucosal IL-17 expression in two gliadin-induced disorders: gluten sensitivity and the autoimmune enteropathy celiac disease. Int Arch Allergy Immunol 152: 75-80. [Crossref]

35. Aziz I, Lewis NR, Hadjivassiliou M (2014) A UK study assessing the population prevalence of self-reported gluten sensitivity and referral characteristics to secondary care. Eur J Gastroenterol Hepatol. 26: 33-9.

36. Volta U, Bardella MT, Calabro A (2014) Study group for non-celiac gluten sensitivity. An Italian prospective multicenter survey on patients suspected of having non-celiac gluten sensitivity. BMC Med. 12: 85 .

37. Vande Voort JL, Murray JA, Lahr BD, Van Dyke CT, Kroning CM, et al. (2009) Lymphocytic duodenosis and the spectrum of celiac disease. Am J Gastroenterol 104: 142-148. [Crossref]

38. Carroccio A, Mansueto P, Iacono G (2012) Non-celiac wheat sensitivity diagnosed by double-blind placebo-controlled challenge: exploring a new clinical entity. $\mathrm{Am} \mathrm{J}$ Gastroenterol. 107: 1898-906.

39. Brottveit M, Beitnes AC, Tollefsen S, Bratlie JE, Jahnsen FL, et al. (2013) Mucosa cytokine response after short-term gluten challenge in celiac disease and non-celiac gluten sensitivity. Am J Gastroenterol 108: 842-850. [Crossref]

40. Volta U, Tovoli F, Cicola R, Parisi C, Fabbri A, et al. (2012) Serological tests in gluten sensitivity (nonceliac gluten intolerance). J Clin Gastroenterol 46: 680-685. [Crossref]

Copyright: (C2016 Nasr I. This is an open-access article distributed under the terms of the Creative Commons Attribution License, which permits unrestricted use, distribution, and reproduction in any medium, provided the original author and source are credited. 